\title{
Common Wet Chemical Agents for Purifying Multiwalled Carbon Nanotubes
}

\author{
Rasel Das, ${ }^{1}$ Md. Eaqub Ali, ${ }^{1}$ Sharifah Bee Abd Hamid, \\ M. S. M. Annuar, ${ }^{2}$ and Seeram Ramakrishna ${ }^{3}$ \\ ${ }^{1}$ Nanotechnology and Catalysis Research Center, University of Malaya, 50603 Kuala Lumpur, Malaysia \\ ${ }^{2}$ Institute of Biological Sciences, Faculty of Science, University of Malaya, 50603 Kuala Lumpur, Malaysia \\ ${ }^{3}$ NUS Centre for Nanofibers and Nanotechnology (NUSCNN), Healthcare and Energy Materials Laboratory, \\ National University of Singapore, Singapore 117584 \\ Correspondence should be addressed to Md. Eaqub Ali; eaqubali@gmail.com
}

Received 31 August 2014; Revised 2 December 2014; Accepted 2 December 2014; Published 22 December 2014

Academic Editor: Chunyi Zhi

Copyright (C) 2014 Rasel Das et al. This is an open access article distributed under the Creative Commons Attribution License, which permits unrestricted use, distribution, and reproduction in any medium, provided the original work is properly cited.

\begin{abstract}
Purification and functionalization of multiwalled carbon nanotubes (MWCNTs) are challenging but vital for their effective applications in various fields including water purification technologies, optoelectronics, biosensors, fuel cells, and electrode arrays. The currently available purification techniques, often complicated and time consuming, yielded shortened and curled MWCNTs that are not suitable for applications in certain fields such as membrane technologies, hybrid catalysis, optoelectronics, and sensor developments. Here we described the $\mathrm{H}_{2} \mathrm{O}_{2}$ synergy on the actions of $\mathrm{HCl}$ and $\mathrm{KOH}$ in purifying and functionalizing pristine MWCNTs. The method $\left(\mathrm{HCl} / \mathrm{H}_{2} \mathrm{O}_{2}\right)$ showed $100 \%$ purification yield as compared to $\mathrm{HCl}$ and $\mathrm{KOH} / \mathrm{H}_{2} \mathrm{O}_{2}$ with purification yields 93.46 and $3.92 \%$, respectively. We probed the findings using transmission electron microscope, energy dispersive $\mathrm{X}$-ray spectroscope, attenuated total reflectance infrared spectroscope, Raman spectroscope, thermal gravimetric analysis, and X-ray powder diffraction. The study is a new avenue for simple, rapid, low cost, and scalable purification of pristine MWCNTs for application in versatile fields.
\end{abstract}

\section{Introduction}

Carbon nanotubes (CNTs) are one of the most fascinating nanomaterials having many attractive and useful physicochemical properties such as mechanical [1,2], thermal [3], electrical [2, 4], and optoelectronic properties [5]. Since CNTs were defined by Iijima in 1991 [6], they have played significant shoot in many domains including water purification technologies [7-9], polymer, and composites [10-12], conductive cable fibers [13], hydrogen storage media [14], biomedical sciences [15], field emission displays [16], electrochemistry, and nanosensors [17], nanoelectrodes and microarrays [18], and many other versatile fields [16].

CNTs are often received or synthesized with other generic impurities such as nonnanotube or amorphous carbons, ash, and metal catalysts with extreme hydrophobicity [19]. The existing CNT synthesis methods added the impurities such as metal catalysts to increase the yield and reduce cost [20].
The level of these unwanted matters depends on the specific method used for CNT synthesis. Whatever might be the method of choice, impurities often hinder CNTs performances and confuse the understanding of their original functionalities, limiting their applications in many important fields. For instance, this triggered CNT aggregation in various polymers [21], which destabilizes polymer's mechanical strength and electrical conductivity [21].

In order to purify pristine CNTs, three classes of CNT purification methods such as chemical, physical, and a combination of both were developed [19]. Chemical purification method was effective because of its selectivity, sensitivity, faster rate kinetics of the oxidation of carbonaceous impurities, and metal catalysts dissolution from the pristine CNTs [22]. In addition, chemical agents are widely available and cost-effective and need simple laboratory settings. In contrast, physical method was involved in removing graphitic sheets and carbon nanospheres from CNT [19]. The method 
was not effective to remove carbon impurities, often complicated and time consuming [19]. Therefore, based on pristine CNT impurities, one can select chemical, physical, or a combination of both in order to get pure CNT with desired properties.

$\mathrm{HCl}, \mathrm{H}_{2} \mathrm{O}_{2}$, and $\mathrm{KOH}$ are easily available simple wet chemicals that are commonly found in most of the ordinary laboratories. Here we treated MWCNTs with $\mathrm{HCl}[23,24]$ as a reference. But $\mathrm{HCl}$ is often incapable of completing removal of nonnanotube impurities [25]. Pristine few walled carbon nanotubes (FWCNTs) were oxidized and purified by $\mathrm{H}_{2} \mathrm{O}_{2}$ [26], but the method thus far is not extensively studied for multiwalled carbon nanotubes (MWCNTs) purification except few [22,27]. Although single-walled carbon nanotubes (SWCNTs) were purified by a mixture of $\mathrm{HCl}$ and $\mathrm{H}_{2} \mathrm{O}_{2}$ [25, 28-31], no study has yet been adopted for MWCNT purification by using that mixture. Therefore, we studied here the synergistic effects of $\mathrm{HCl} / \mathrm{H}_{2} \mathrm{O}_{2}$ mixture for improving the carbon yield and getting purified well graphitic layer of MWCNTs. A basic treatment involving $\mathrm{NH}_{4} \mathrm{OH} / \mathrm{H}_{2} \mathrm{O}_{2}$ was effective in purifying MWCNTs [32]. We developed and applied another basic wet oxidizing technique involving a mixture of $\mathrm{KOH} / \mathrm{H}_{2} \mathrm{O}_{2}$ in purifying MWCNTs. The methods $\left(\mathrm{HCl}, \mathrm{HCl} / \mathrm{H}_{2} \mathrm{O}_{2}\right.$, and $\left.\mathrm{KOH} / \mathrm{H}_{2} \mathrm{O}_{2}\right)$ were effective to get oxidized MWCNTs, but high purification yield was observed for $\mathrm{HCl} / \mathrm{H}_{2} \mathrm{O}_{2}$ compared with $\mathrm{HCl}$ and $\mathrm{KOH} / \mathrm{H}_{2} \mathrm{O}_{2}$. We focused on MWCNTs because of their low preparation costs and availability in large quantities.

Transmission electron microscope (TEM) was used to study the morphological changes of MWCNTs. Energy dispersive X-ray spectroscope (EDX) was used for the analysis of elemental composition and state of impurities. Attenuated total reflectance infrared (ATR-IR) spectroscope was performed to estimate the degree and type of functionalization. Raman spectroscope was conducted to measure the defects and character of graphite bands, and thermal gravimetric analysis (TGA) was used to record the mass profile of pristine and treated MWCNTs. Finally, X-ray powder diffraction (XRD) was used to define crystallinity, in-plane regularity, and lattice profiles.

\section{Experimental Section}

2.1. Materials. Pristine MWCNTs of $12 \pm 5$ and $4 \mathrm{~nm}$ in outer and inner diameters and $>1 \mu \mathrm{m}$ in length were bought from Bayer MaterialScience AG (Germany). The tubes were prepared by catalytic chemical vapor deposition (CCVD) and contained $>95 \%$ carbon by weight and were used as received. Hydrochloric acid and hydrogen peroxide were purchased from Merck Sdn Bhd. (Malaysia). Potassium hydroxide, ethanol, and acetone were purchased from Sigma-Aldrich Sdn Bhd. (Malaysia). The purity of all reagents was $\geq 99 \%$ except hydrochloric acid (37\%), hydrogen peroxide (30\%), and ethanol $(70 \%)$ in water.

2.2. Instrumentation. TEM (Hitachi-HT7700, Japan) was used for the morphological characterizations of the MWCNTs. It was performed at $120 \mathrm{kV}$. An EDX coupled with a FE-SEM (QUANTA FEG 450, FEI, USA) was used for elemental analysis. An X-Max Silicon Drift detector (Oxford, $\mathrm{UK}$ ) of $80 \mathrm{~mm}^{2}$ was used to identify the elements and energy and relative intensity of emitted $\mathrm{X}$-rays were analyzed at $10 \mathrm{Kev}$. ATR-IR spectra were recorded on a $\mathrm{KBr}$ using an IR spectrometer (IFS 66 v/S, Bruker, Germany). Raman spectra were acquired for $10 \mathrm{~min}$ at a laser power of 100 on $\mathrm{Ar}^{+}$laser $(514 \mathrm{~nm})$ focused (50X objective) on a spot size of about 1.5$2.0 \mu \mathrm{m}$ (Renishaw inVia, UK). TGA (TGA/SDTA 851, Mettler Toledo, USA) was performed under air flow $(50 \mathrm{~mL})$ between 25 and $1000^{\circ} \mathrm{C}$ at $10^{\circ} \mathrm{C} / \mathrm{min}$. XRD diffracted patterns were collected at $\mathrm{Ni}$ filtered $\mathrm{Cu} \mathrm{K} \alpha$ radiation $(40 \mathrm{kV}, 40 \mathrm{~mA}, \lambda=$ $1.5401 \AA$ ) (XRD/D8, Bruker, Germany).

2.3. Wet Chemical Treatments of MWCNTs. Three wet chemical treatments were performed to purify and oxidize the asobtained pristine MWCNTs.

(i) $\mathrm{HCl}$ Treatment. Pristine MWCNTs $(0.5 \mathrm{~g})$ were treated with $100 \mathrm{~mL}$ of hydrochloric acid (36 wt\%) and sonicated at $50^{\circ} \mathrm{C}$ for $3 \mathrm{~h}$ in an ultrasonication bath (Series 400; POWERSONIC, $40 \mathrm{KHz}$; Korea) [24]. The method was as a reference.

(ii) $\mathrm{HCl} / \mathrm{H}_{2} \mathrm{O}_{2}$ Treatment. Pristine MWCNTs (0.5 g) were dispersed into $25 \mathrm{~mL}$ mixture $(70: 30)$ of hydrochloric acid (36 wt $\%)$ and hydrogen peroxide $(30 \mathrm{wt} \%)$, and the final mixture was sonicated at $50^{\circ} \mathrm{C}$ for $5 \mathrm{~h}$ at $40 \mathrm{KHz}$.

(iii) $\mathrm{KOH} / \mathrm{H}_{2} \mathrm{O}_{2}$ Treatment. Pristine MWCNTs (0.5 g) were dispersed into a $20 \mathrm{~mL}$ mixture $(50: 50)$ of potassium hydroxide (25 wt $\%)$ and hydrogen peroxide (30 wt $\%)$, and the mixture was sonicated at $50^{\circ} \mathrm{C}$ for $5 \mathrm{~h}$ at $40 \mathrm{KHz}$.

2.4. Removal of the Residual Impurities. All treated MWCNTs were extracted from the residual acids, bases, metallic byproducts, and carbonaceous impurities by repeated cycle of dilution and centrifugation (dissolved in $1 \mathrm{~L}$ of deionized water and centrifuged (Eppendorf-5430R; Germany) at $7000 \mathrm{rpm}$ for $30 \mathrm{~min}$ ). The supernatant was carefully collected when the MWCNTs were precipitated at the bottom of the polyethylene centrifuge tube. The procedure was repeated 5-6 times until the resistivity of the supernatant was greater than $0.5 \mathrm{M} \Omega \cdot \mathrm{cm}$ and $\mathrm{pH}$ was $\sim 7.0$. The treated MWCNTs were then rinsed with ethanol (70 wt\%) and dried overnight in a vacuum oven at $100^{\circ} \mathrm{C}$.

\section{Results and Discussion}

3.1. Predicted Chemical Reactions of $\mathrm{HCl}, \mathrm{H}_{2} \mathrm{O}_{2}$, and $\mathrm{KOH}$ with MWCNTs. To get pure MWCNTs, agents such as $\mathrm{HCl}$, $\mathrm{HCl} / \mathrm{H}_{2} \mathrm{O}_{2}$, and $\mathrm{KOH} / \mathrm{H}_{2} \mathrm{O}_{2}$ were found to be promising (Figure 1$)$. The method $\left(\mathrm{HCl} / \mathrm{H}_{2} \mathrm{O}_{2}\right)$ can purify MWCNTs through different routes. The metals that are usually present in pristine CNTs act as catalysts to produce hydroxyl radical $\left(\mathrm{OH}^{\circ}\right)$ through Fenton's chemistry [33] (Figure 1(a)), which is stronger oxidizing agent than $\mathrm{H}_{2} \mathrm{O}_{2}$ :

$\mathrm{H}_{2} \mathrm{O}_{2}+$ metal (reduced) $\longrightarrow \mathrm{OH}^{\mathrm{O}}+\mathrm{OH}^{-}+$metal (oxidized) 


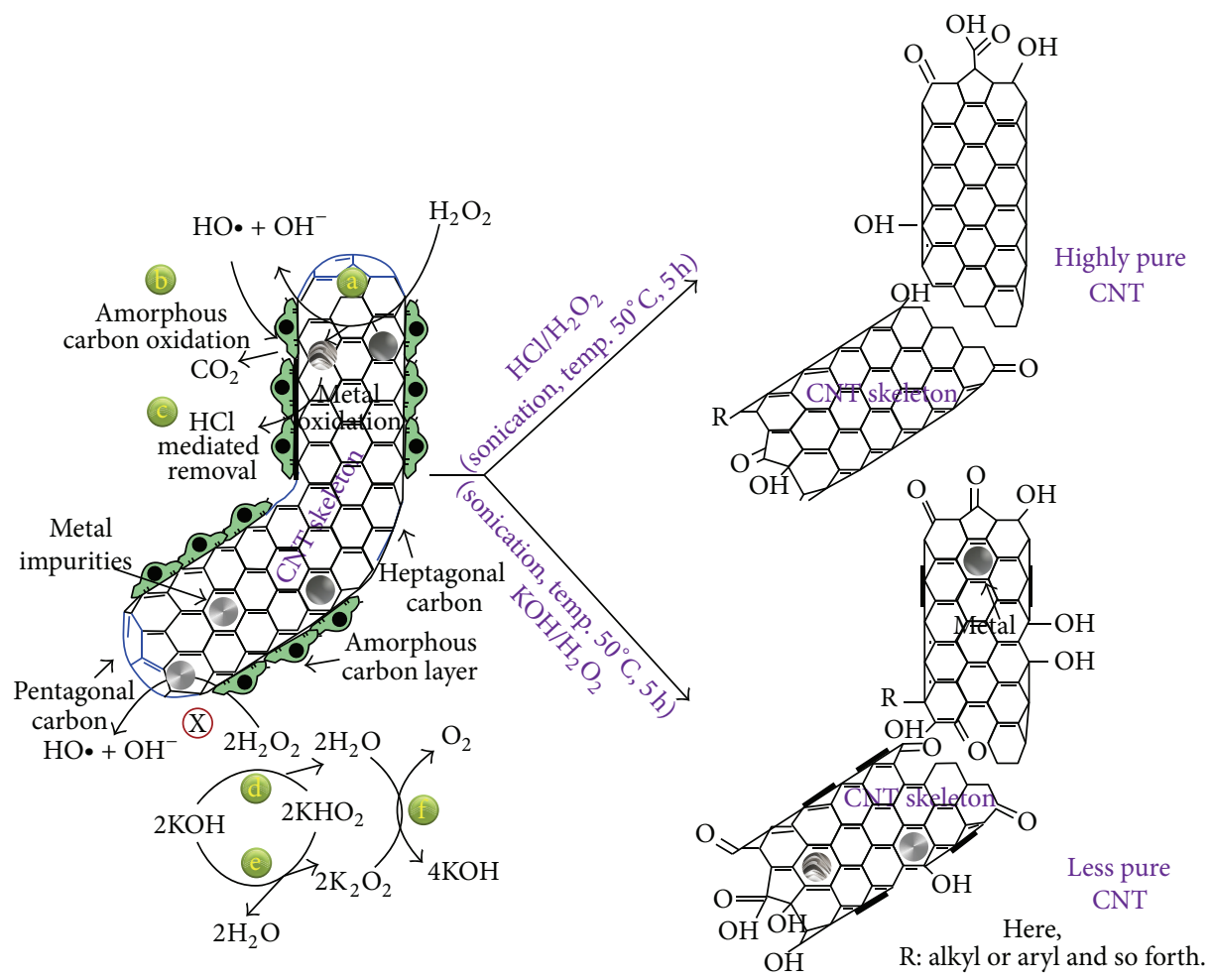

FIgURE 1: Schematic of the localized catalytic reactions of $\mathrm{HCl} / \mathrm{H}_{2} \mathrm{O}_{2}(\mathrm{a}),(\mathrm{b})$, and (c) and $\mathrm{KOH} / \mathrm{H}_{2} \mathrm{O}_{2}(\mathrm{~d})$, (e), and (f) with pristine MWCNTs.

The radical $\left(\mathrm{OH}^{\circ}\right)$ is then reacted with amorphous carbon impurities of pristine CNTs [22] and converted them into $\mathrm{CO}_{2}[25]$ (Figure 1(b)):

$$
4 \mathrm{OH}^{\mathrm{O}}+\mathrm{C} \longrightarrow \mathrm{CO}_{2}+2 \mathrm{H}_{2} \mathrm{O}
$$

The oxidized metals and other impurities are then dissolved into $\mathrm{HCl}$ (Figure $1(\mathrm{c})$ ), which are subsequently removed through filtering and washings.

However, a mixture of $\mathrm{KOH}$ and $\mathrm{H}_{2} \mathrm{O}_{2}$ was unable to complete amorphous carbon oxidation and removal of metal impurities from MWCNT. This is because of the chemical reactions between $\mathrm{KOH}$ and $\mathrm{H}_{2} \mathrm{O}_{2}$ (Figures $1(\mathrm{~d}), 1(\mathrm{e}$ ), and $1(\mathrm{f}))$. $\mathrm{KOH}$ decreases the availability of $\mathrm{H}_{2} \mathrm{O}_{2}$ in the system, so there is the least chance to produce free radicals and other etching agents. The ultimate products of the reaction were $\mathrm{KOH}$ and $\mathrm{O}_{2}$. Oxygen was evaporated while $\mathrm{KOH}$ may have some chemical interactions with amorphous carbons, which might be negligible to remove MWCNT core impurities.

3.2. TEM Analysis. TEM microscope was used to closely examine the contents of amorphous carbon and location of metal catalysts trapped into the tubular interstitial spaces of pristine and treated MWCNTs (Figure 2). Pristine MWCNTs reflected clumped, cloudy, and amorphous carbon containing MWCNTs (Figure 2(a)). The impure carbonaceous particles were found to be wrapped around the nanotube structures, and metal catalysts were trapped into the MWCNTs. Although the overall amorphous carbons and metals were removed from the nanotube surface after $\mathrm{HCl}$ treatment, some MWCNTs were thick suggesting small percentages of nonnanotube carbonaceous agents and impurities may present on MWCNT surfaces (Figure 2(b)). The $\mathrm{HCl} / \mathrm{H}_{2} \mathrm{O}_{2}$ treatment produced much cleaner, fresh, and complete amorphous carbon and metals-free MWCNTs and the nanotubes appeared in thin and loosely connected bundles (Figure 2(c)). Although the oxidizing strength of $\mathrm{H}_{2} \mathrm{O}_{2}$ is high (Pka 11.6), it did not produce vigorous CNT fragmentations upon the purification process in presence of $\mathrm{HCl}$. In the $\mathrm{KOH} / \mathrm{H}_{2} \mathrm{O}_{2}$ treatment, some of the amorphous carbons from MWCNT surfaces were removed. However, the effects were local since the presence of some nonnanotube carbon impurities was globally obvious (Figure 2(d)) and the nanotubes appeared more flattened and thick than those of $\mathrm{HCl}$ (Figure 2(b)) and $\mathrm{HCl} / \mathrm{H}_{2} \mathrm{O}_{2}$ (Figure 2(c)) treated MWCNTs.

3.3. EDX Analysis. EDX is a significant characterization tool for measuring the extent of CNT oxidation and elemental composition [22]. EDX findings of the pristine and treated MWCNTs are shown in Figure 3 and representative analysis is listed in Table 1. Purification yield of pristine and treated MWCNTs was calculated based on the following:

$$
\text { Purification yield (\%) : } \frac{W_{0}-W_{t}}{W_{0}} \times 100 \text {, }
$$

where $W_{0}$ is the metal content of the pristine MWCNT (\%) and $W_{t}$ is the metal content of purified MWCNT (\%).

As we observed in Table 1, by far, the largest element in the as-received pristine MWCNT is carbon (either graphitic 

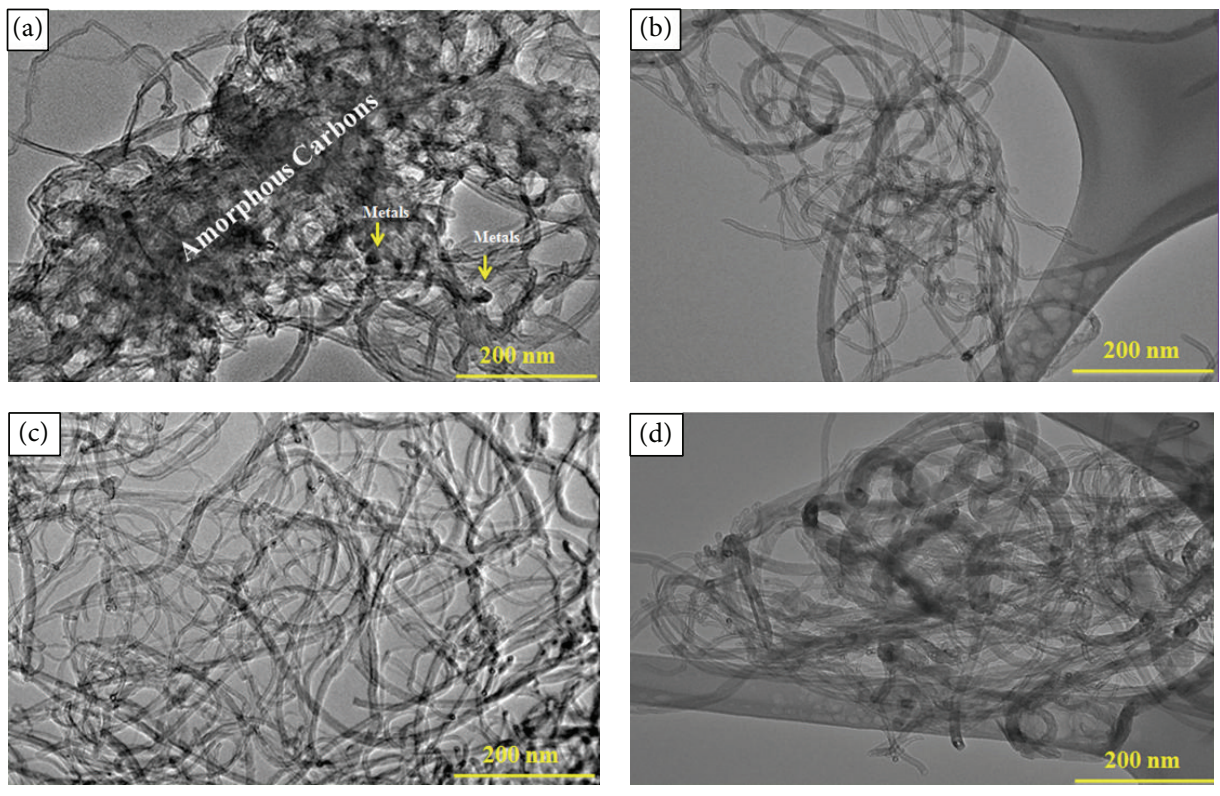

Figure 2: TEM images of pristine (a), $\mathrm{HCl}(\mathrm{b}), \mathrm{HCl} / \mathrm{H}_{2} \mathrm{O}_{2}$ (c), and $\mathrm{KOH} / \mathrm{H}_{2} \mathrm{O}_{2}$ treated MWCNTs (d).

TABLE 1: Elemental analysis of before and after MWCNT treatments in this study.

\begin{tabular}{lccccccccc}
\hline \multirow{2}{*}{ Specimen } & \multirow{2}{*}{ Treatment time (h) } & \multicolumn{9}{c}{ Elemental composition (Wt\%) } \\
& & $\mathrm{C}$ & $\mathrm{O}$ & $\mathrm{Co}$ & $\mathrm{Mn}$ & $\mathrm{Al}$ & $\mathrm{Mg}$ & Sum & Purification yield (\%) \\
\hline Pristine $\mathrm{MWCNT}$ & 0 & 97.35 & 1.12 & 0.48 & 0.46 & 0.3 & 0.29 & 100 & - \\
$\mathrm{MWCNT}-\mathrm{HCl}$ & 5 & 98.77 & 1.13 & 0 & 0 & 0.1 & 0 & 100 & 93.46 \\
$\mathrm{MWCNT}-\mathrm{HCl} / \mathrm{H}_{2} \mathrm{O}_{2}$ & 5 & 98.78 & 1.22 & 0 & 0 & 0 & 0 & 100 & 100 \\
$\mathrm{MWCNT}-\mathrm{KOH} / \mathrm{H}_{2} \mathrm{O}_{2}$ & 5 & 95.19 & 3.34 & 0.45 & 0.42 & 0.3 & 0.3 & 100 & 3.92 \\
\hline
\end{tabular}

or amorphous), with some extent of oxygen (Figure 3(a)). However, pristine MWCNTs were highly contaminated with metal impurities such as Co, Mn, Al, and Mg (Figure 3(a)). After wet chemical agent treatments, it was observed that the amount of graphitic carbons was slightly increased, since most of the metal impurities diminish significantly, given the established role of $\mathrm{HCl}$ and $\mathrm{HCl} / \mathrm{H}_{2} \mathrm{O}_{2}$ as good purification yields of 93.46 and $100 \%$, respectively (Figures 3(b) and $3(\mathrm{c})$ ). In contrast, $\mathrm{KOH} / \mathrm{H}_{2} \mathrm{O}_{2}$ was incapable of completing removal of metal impurities and showed lowest purification yield $3.92 \%$ (Figure 3(d)). Herein we hypothesized that the $\mathrm{HCl} / \mathrm{H}_{2} \mathrm{O}_{2}$ mixture can be a judicial choice for the complete purification of pristine MWCNTs compared with $\mathrm{HCl}$ and $\mathrm{KOH} / \mathrm{H}_{2} \mathrm{O}_{2}$ treatments.

3.4. ATR-IR Analysis. ATR-IR spectroscope was performed for characterizing the functionalities produced following wet chemical treatments $\left(\mathrm{HCl}, \mathrm{HCl} / \mathrm{H}_{2} \mathrm{O}_{2}\right.$, and $\left.\mathrm{KOH} / \mathrm{H}_{2} \mathrm{O}_{2}\right)$ resulting in MWCNT purifications. The IR spectra of the pristine and treated MWCNTs are depicted in Figure 4. The dominant IR spectrum at $3409 \mathrm{~cm}^{-1}$ was assigned to the stretching vibration of intermolecularly hydrogen bonded $\mathrm{OH}$ : OH groups (Figures 4(a), 4(b), 4(c), and 4(d)) [34, 35]. The intensity of this band was low in pristine MWCNTs
(Figure 4(a)), but it was significantly increased and broadened following wet chemical treatments and purifications especially at $\mathrm{KOH} / \mathrm{H}_{2} \mathrm{O}_{2}$ (Figure $4(\mathrm{~d})$ ) indicating the formation of huge $-\mathrm{OH}$ groups upon chemical treatments [36]. The IR transmittance peak at $2907 \mathrm{~cm}^{-1}$ which was dominant in $\mathrm{HCl} / \mathrm{H}_{2} \mathrm{O}_{2}$ (Figure $4(\mathrm{c})$ ) and $\mathrm{KOH} / \mathrm{H}_{2} \mathrm{O}_{2}$ (Figure $4(\mathrm{~d})$ ) treated MWCNTs was assigned to $\mathrm{sp}^{2}$ and $\mathrm{sp}^{3} \mathrm{C}-\mathrm{H}$ stretching vibrations [37]. The transmittance bands at 2422 and $2279 \mathrm{~cm}^{-1}$ were observed for pristine (Figure 4(a)), $\mathrm{HCl} /$ $\mathrm{H}_{2} \mathrm{O}_{2}$ (Figure $4(\mathrm{c})$ ), and $\mathrm{KOH} / \mathrm{H}_{2} \mathrm{O}_{2}$ (Figure $4(\mathrm{~d})$ ), but was absent in the $\mathrm{HCl}$ (Figure 4(b)) treated MWCNTs, respectively, may pointing out the grafting of some $\mathrm{CO}$ and $\mathrm{COO}^{-}$ groups, respectively [38]. The peak at $1630 \mathrm{~cm}^{-1}$ (Figures 4(a), 4(b), 4(c), and 4(d)) was due to the stretching vibration of $\mathrm{C}=\mathrm{C}$ [36] and $\mathrm{C}=\mathrm{O}$ of quinone [38] that was created on MWCNT surfaces following wet chemical treatments. The highest intensity of this peak was found following $\mathrm{KOH} / \mathrm{H}_{2} \mathrm{O}_{2}$ treatment (Figure $4(\mathrm{~d})$ ), suggesting the presence of more -CO groups. The prominent peak at $1044 \mathrm{~cm}^{-1}$ (Figures 4(a), 4(b), 4(c), and 4(d)) was due to -OH group generated because of the atmospheric oxidation or oxidation from wet chemical treatments [38]. In addition, a peak that appeared at $804 \mathrm{~cm}^{-1}$ was due to epoxy and oxirane rings evolved from $\mathrm{C}-\mathrm{O}-$ groups and ring deformation of 


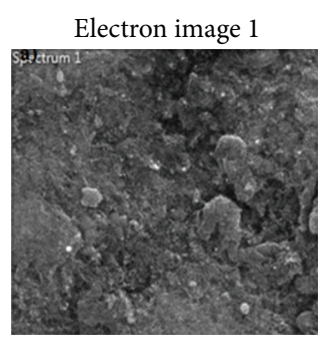

$10 \mu \mathrm{m}$

Electron image 2

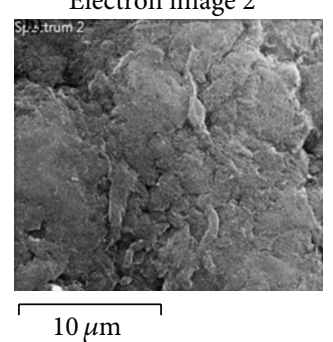

$10 \mu \mathrm{m}$

Electron image 3

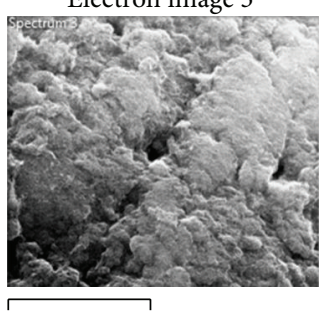

$10 \mu \mathrm{m}$

Electron image 4

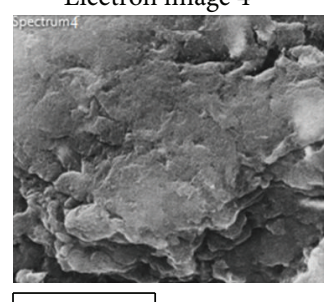

$10 \mu \mathrm{m}$
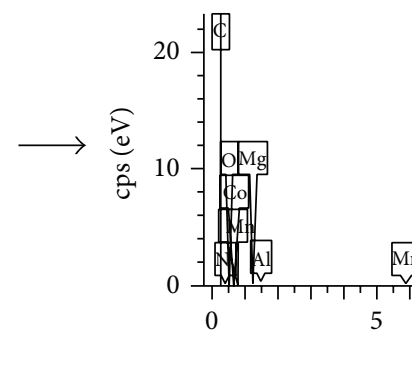

(a)
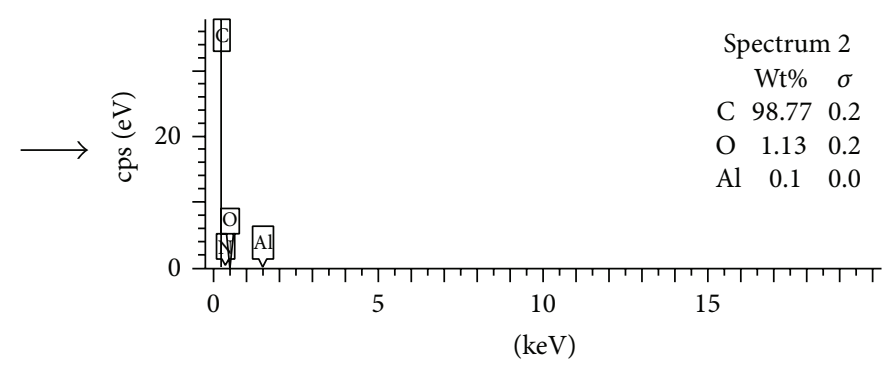

(b)
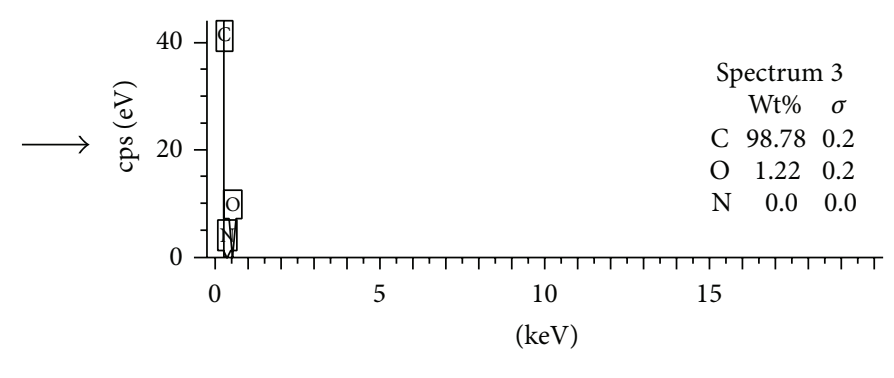

(c)
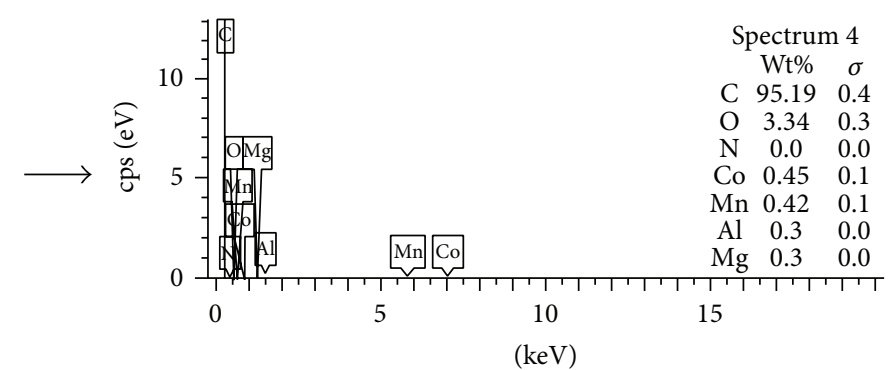

(d)

FIGURE 3: EDX profiles of pristine (a), $\mathrm{HCl}(\mathrm{b}), \mathrm{HCl} / \mathrm{H}_{2} \mathrm{O}_{2}$ (c), and $\mathrm{KOH} / \mathrm{H}_{2} \mathrm{O}_{2}$ (d) treated MWCNTs.

substituted aromatic structures [36]. Some weak peaks that appeared in $2500-3500 \mathrm{~cm}^{-1}$ region in pristine MWCNTs (shown by asterisks) (Figure 4(a)) disappeared following chemical treatments (Figures 4(b), 4(c), and 4(d)). It clarifies the presence of some minor functional groups of the pristine MWCNTs anchored by amorphous carbons and other carbonaceous fragments which were successfully removed by wet chemicals processing.

3.5. Raman Spectroscopy. Typically, MWCNT represents two significant high frequency bands called D- and G-bands at
1330 and $1585 \mathrm{~cm}^{-1}$ for CNT structural defects and graphite in-plane vibration, respectively $[39,40]$. In this study, D- and G-bands appeared at $\sim 1349$ and $\sim 1588 \mathrm{~cm}^{-1}$ both in treated and pristine MWCNTs, respectively (Figure 5).

The intensity of the $\mathrm{D}$-band which is induced by nonzero center phonon mode usually depends on the presence of disordered carbon atomic networks [31, 41]. However, Figure 5 shows the D-band intensities were practically constant in both pristine and treated MWCNTs. This indicates that MWCNTs were purified with less defects density. This might be due to the milder reaction conditions among graphitic 


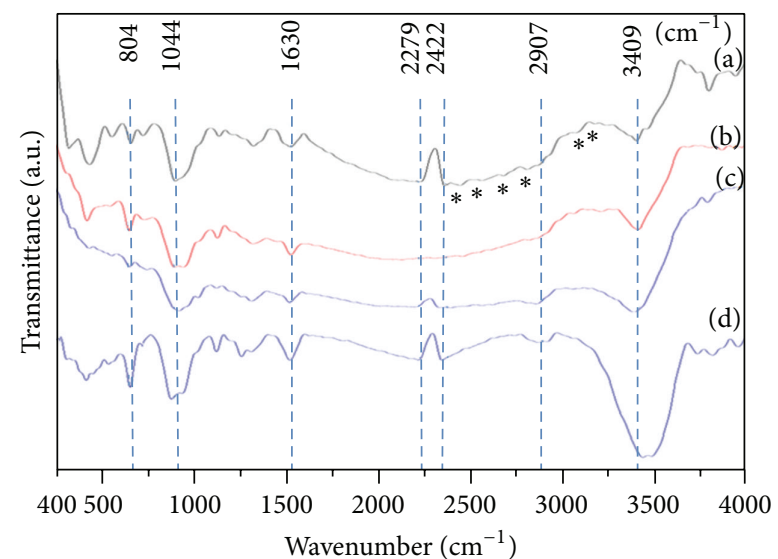

FIgURE 4: ATR-IR spectra of pristine (a), $\mathrm{HCl}$ (b), $\mathrm{HCl} / \mathrm{H}_{2} \mathrm{O}_{2}$ (c), and $\mathrm{KOH} / \mathrm{H}_{2} \mathrm{O}_{2}$ (d) treated MWCNTs.

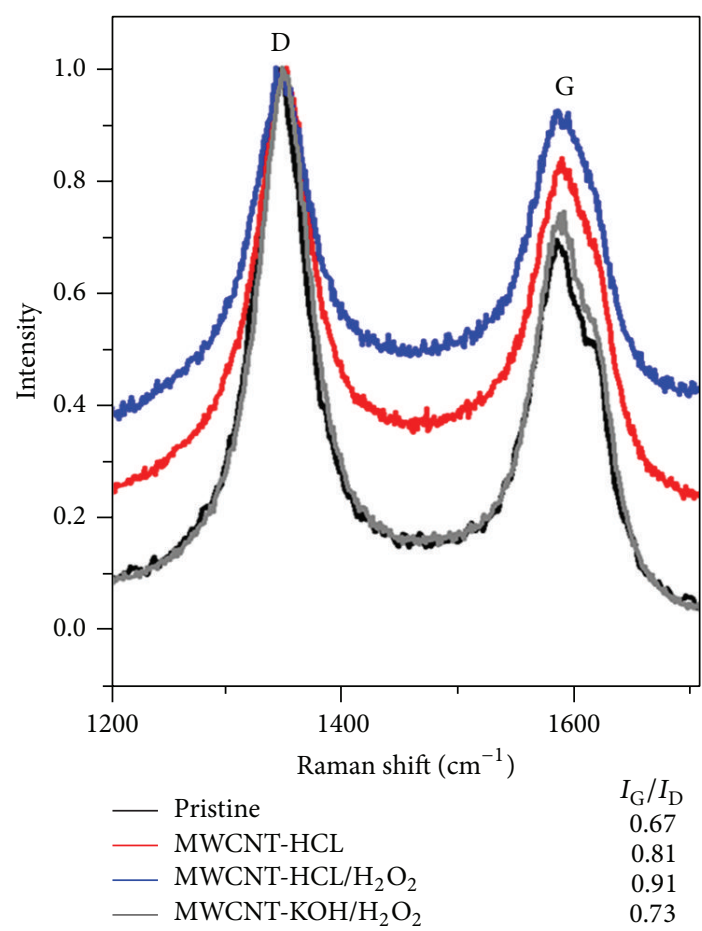

FIGURE 5: Normalized Raman spectra of pristine and treated MWCNTs.

carbons of MWCNTs and $\mathrm{HCl}, \mathrm{HCl} / \mathrm{H}_{2} \mathrm{O}_{2}$ and $\mathrm{KOH} / \mathrm{H}_{2} \mathrm{O}_{2}$. The etching properties of $\mathrm{OH}^{\circ}$, which was generated by Fenton's chemistry [33], may have direct affinity to oxidize amorphous carbons due to the presence of many active sites on it [32] (Figure 1(b)) rather than oxidizing graphitic layer's carbon atoms. On the other hand, $\mathrm{KOH} / \mathrm{H}_{2} \mathrm{O}_{2}$ was unable to directly react with graphitic skeleton, since most of the amorphous carbons were wrapped around the pristine MWCNTs (Figures 1(d), 1(e), and 1(f)). However, the G-band intensities were significantly increased in treated MWCNTs especially for $\mathrm{HCl} / \mathrm{H}_{2} \mathrm{O}_{2}$ treated MWCNTs. This clearly indicates that the $\mathrm{HCl} / \mathrm{H}_{2} \mathrm{O}_{2}$ removed nonnanotube carbon

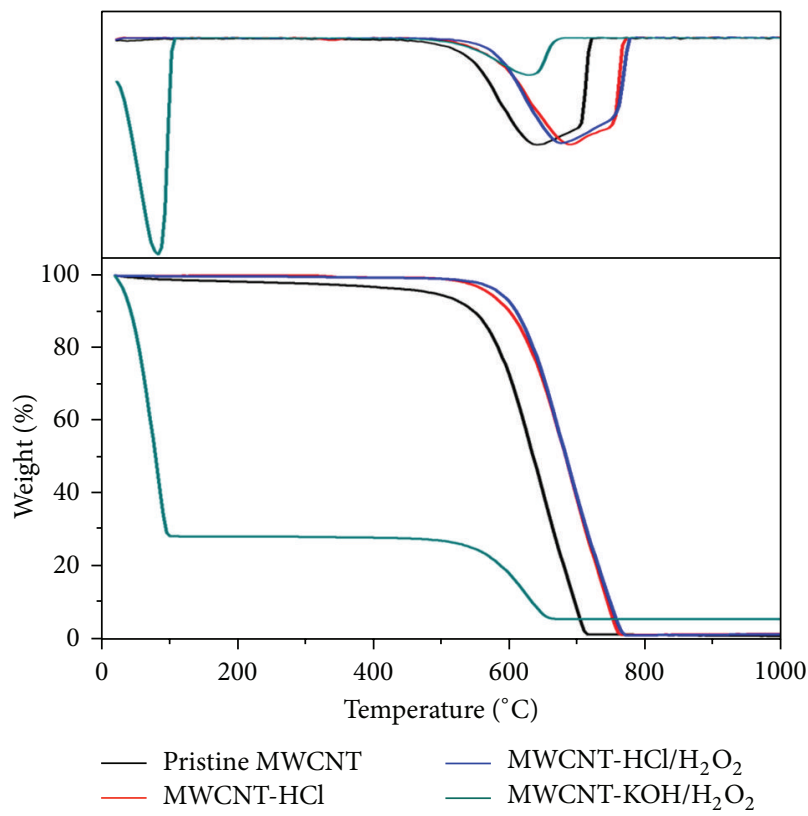

FIGURE 6: TGA curves of pristine and treated MWCNTs (down) and their derivative spectra (up).

impurities and metal catalysts and generated well graphitic MWCNT structure [41] compared to $\mathrm{HCl}$ and $\mathrm{KOH} / \mathrm{H}_{2} \mathrm{O}_{2}$ while maintaining intact MWCNT integrity (Figure 5).

Finally, the purity states of the pristine and treated MWCNTs were compared from the intensity ratio of the $\mathrm{G}\left(I_{\mathrm{G}}\right)$ and D-bands $\left(I_{\mathrm{D}}\right)$ [32]. The highest ratio (0.91) of $I_{\mathrm{G}} / I_{\mathrm{D}}$ was found for $\mathrm{HCl} / \mathrm{H}_{2} \mathrm{O}_{2}$ treated MWCNTs, suggesting the better efficiency of $\mathrm{HCl} / \mathrm{H}_{2} \mathrm{O}_{2}$ in removing amorphous and carbonaceous materials from MWCNTs [26]. The $I_{\mathrm{G}} / I_{\mathrm{D}}$ ratios for $\mathrm{HCl}(0.81)$ and $\mathrm{KOH} / \mathrm{H}_{2} \mathrm{O}_{2}(0.73)$ treated MWCNTs were less effective in complete removal of nonnanotube carbon impurities and metal catalysts from pristine MWCNT surfaces (Figure 5).

3.6. TGA Analysis. TGA was performed to measure the amorphous carbons, oxidation defects, and overall quality of purified MWCNTs. TGA of pristine and treated MWCNTs (down) with their derivative spectra (up) are presented in Figure 6. By oxidation temperature, herein, we mean the temperature where MWCNTs lose their weight and thus show the highest derivative weight curve. This can define the stability of MWCNTs at a given temperature. At first pristine and $\mathrm{KOH} / \mathrm{H}_{2} \mathrm{O}_{2}$ treated MWCNTs showed lowest decomposition temperatures at around $100^{\circ} \mathrm{C}$ and lost their weights of about 1 and $70 \%$, respectively, which correspond to the pyrolytic evolution of hydroxyl and/or water [32]. Typically, amorphous carbons oxidized at around $500^{\circ} \mathrm{C}$ [42] due to their lower activation energy and the presence of many heat sensitive active sites [32]. TGA of pristine and $\mathrm{KOH} / \mathrm{H}_{2} \mathrm{O}_{2}$ treated MWCNTs showed highest decomposition temperatures at $550^{\circ} \mathrm{C}$ and loss of their weights of about 5 and $75 \%$, respectively (Figure 6). However, pure and well graphitic carbon skeletons are commonly reacted at relatively 


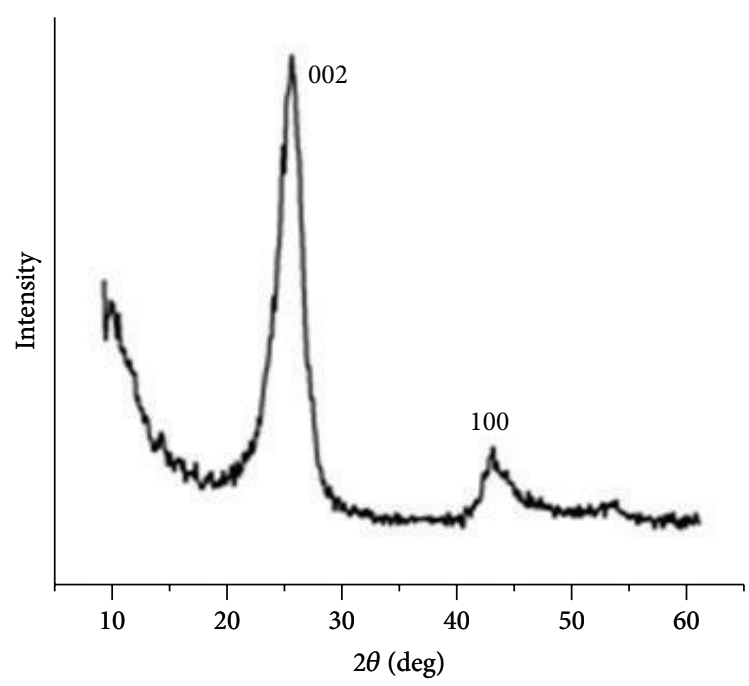

(a)

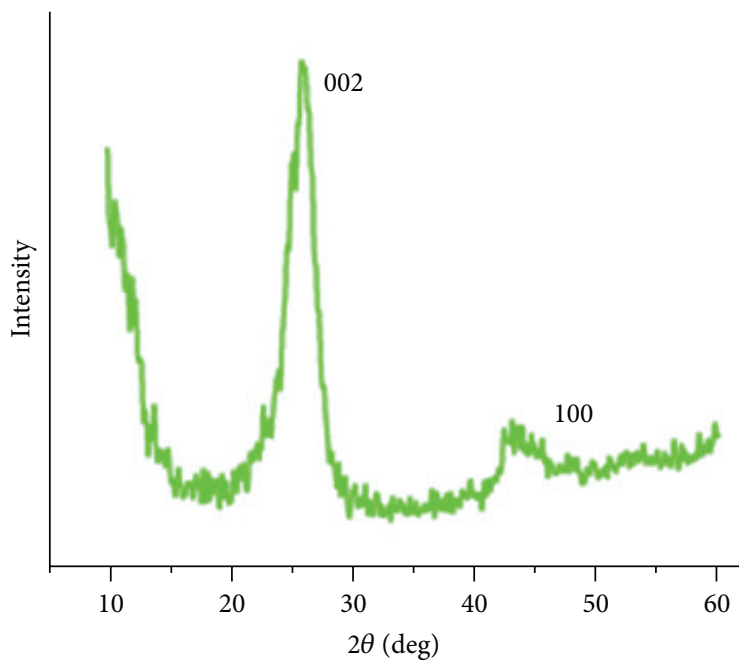

(c)

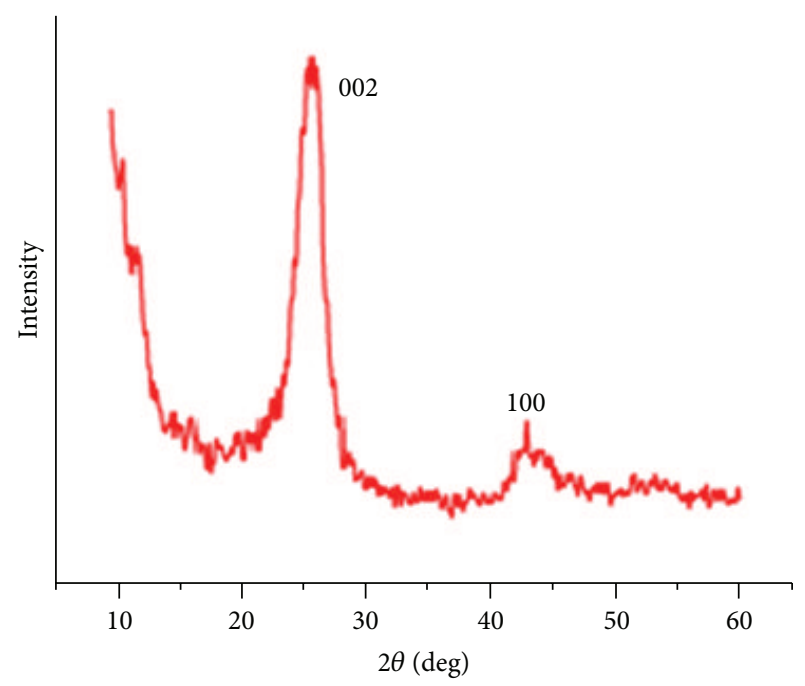

(b)

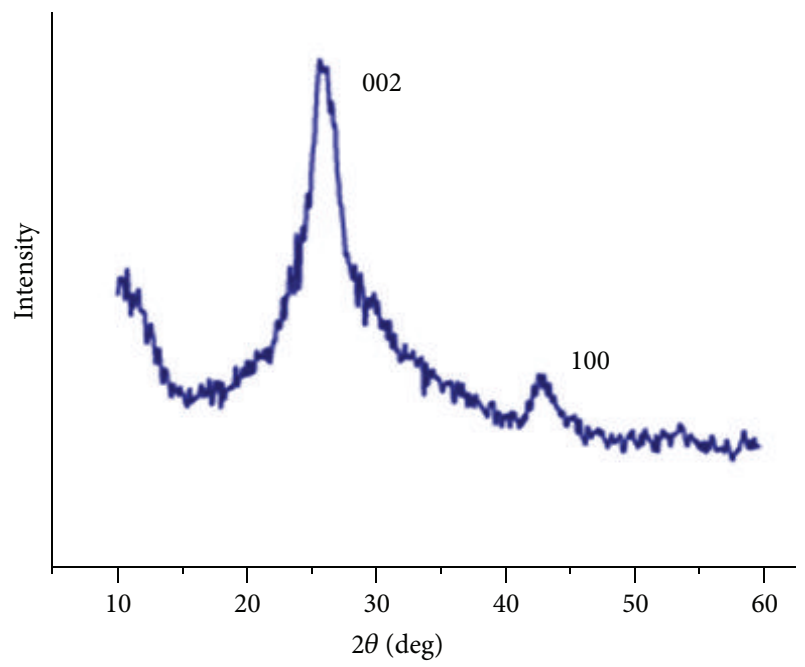

(d)

FIgURE 7: XRD patterns of pristine (a), $\mathrm{HCl}(\mathrm{b}), \mathrm{HCl} / \mathrm{H}_{2} \mathrm{O}_{2}$ (c), and $\mathrm{KOH} / \mathrm{H}_{2} \mathrm{O}_{2}$ (d) treated MWCNTs.

higher temperature ranges between 600 and $700^{\circ} \mathrm{C}$ [43]. TGA of $\mathrm{HCl}$ and $\mathrm{HCl} / \mathrm{H}_{2} \mathrm{O}_{2}$ (Figure 6) treated MWCNTs started to weight loss of about 5 and $10 \%$, respectively, at $600^{\circ} \mathrm{C}$, suggesting the efficacy of these chemicals in purifying MWCNTs. Remaining disordered carbons present in all MWCNTs showed complete weight loss between 650 and $800^{\circ} \mathrm{C}[32]$.

3.7. XRD Analysis. The two characteristic XRD peaks of MWCNTs for two important phases such as 002 and 100 in the range of $2 \theta=\left(10-60^{\circ}\right)$ (Figure 7) were followed in this study [44]. The peak characterizing the interlayer spacing (002) of CNT tubular walls was observed at $2 \theta=26.08$ and $26.03^{\circ}$ (mean) for pristine (Figure $7(\mathrm{a})$ ) and treated MWCNTs (Figures 7(b), 7(c), and 7(d)), respectively. This indicates that the graphitic structure of MWCNTs was not destroyed during the purification process [45]. The peak defining in-plane regularity (100) appeared at $2 \theta=43.34$ and $43.26^{\circ}$ (mean) for pristine (Figure $7(\mathrm{a})$ ) and treated MWCNTs (Figures 7(b), 7(c), and 7(d)), respectively. When all parts of MWCNTs are absolutely parallel to the 002 plane, the intensity of the peak 100 often decreases or vanishes [27]. Presence of nonnanotube impurities and debris can change carbon ordering and increase roughness of the CNT surface lattice structure. The intensity at plane 100 was $8.01<10.44$ $<12.25<19.37$ for $\mathrm{HCl} / \mathrm{H}_{2} \mathrm{O}_{2}$ (Figure 7 (c)), $\mathrm{HCl}$ (Figure 7(b)), $\mathrm{KOH} / \mathrm{H}_{2} \mathrm{O}_{2}$ (Figure $7(\mathrm{~d})$ ), and pristine MWCNTs (Figure 7(a)), respectively. This suggested that the $\mathrm{HCl} / \mathrm{H}_{2} \mathrm{O}_{2}$ treated MWCNT had well parallel MWCNT lattice structure because of complete elimination of nonnanotube impurities as compared to $\mathrm{HCl}$ and $\mathrm{KOH} / \mathrm{H}_{2} \mathrm{O}_{2}$.

\section{Conclusions}

The purification of MWCNTs using three common wet chemical agents $\left(\mathrm{HCl}, \mathrm{HCl} / \mathrm{H}_{2} \mathrm{O}_{2}\right.$, and $\left.\mathrm{KOH} / \mathrm{H}_{2} \mathrm{O}_{2}\right)$ is presented. 
The $\mathrm{HCl} / \mathrm{H}_{2} \mathrm{O}_{2}$ mixture produced more cleanly and well orderly MWCNT skeleton compared with that of ordinary $\mathrm{HCl}$. Although considerable removal of amorphous carbon is possible with $\mathrm{KOH} / \mathrm{H}_{2} \mathrm{O}_{2}$ treatment, complete MWCNT purification is out of place. Thus the MWCNT purities depend on the nature of wet chemical agents and impurities present in the overall MWCNT structure.

\section{Conflict of Interests}

The authors declare no conflict of interests.

\section{Acknowledgments}

Rasel Das is a recipient of the University of Malaya Bright Spark Scholarship. The research is supported by HIR Project no. H-21001-F000032, NND Project no. 53-02031090, and UMRG (RP022-2012A) given to Professor Sharifah Bee Abd Hamid.

\section{References}

[1] E. W. Wong, P. E. Sheehan, and C. M. Lieber, "Nanobeam mechanics: elasticity, strength, and toughness of nanorods and nanotubes," Science, vol. 277, no. 5334, pp. 1971-1975, 1997.

[2] Z. Y. Liu, B. L. Xiao, W. G. Wang, and Z. Y. Ma, “Tensile strength and electrical conductivity of carbon nanotube reinforced aluminum matrix composites fabricated by powder metallurgy combined with friction stir processing," Journal of Materials Science \& Technology, vol. 30, no. 7, pp. 649-655, 2014.

[3] J. Hone, B. Batlogg, Z. Benes, A. T. Johnson, and J. E. Fischer, "Quantized phonon spectrum of single-wall carbon nanotubes," Science, vol. 289, no. 5485, pp. 1730-1733, 2000.

[4] S. J. Tans, A. R. M. Verschueren, and C. Dekker, "Roomtemperature transistor based on a single carbon nanotube," Nature, vol. 393, no. 6680, pp. 49-52, 1998.

[5] P. Avouris and J. Chen, "Nanotube electronics and optoelectronics," Materials Today, vol. 9, no. 10, pp. 46-54, 2006.

[6] S. Iijima, "Helical microtubules of graphitic carbon," Nature, vol. 354, no. 6348, pp. 56-58, 1991.

[7] R. Das, S. B. A. Hamid, M. E. Ali, A. F. Ismail, M. Annuar, and S. Ramakrishna, "Multifunctional carbon nanotubes in water treatment: the present, past and future," Desalination, vol. 354, pp. 160-179, 2014.

[8] R. Das, M. E. Ali, S. B. A. Hamid, S. Ramakrishna, and Z. Z. Chowdhury, "Carbon nanotube membranes for water purification: a bright future in water desalination," Desalination, vol. 336, no. 1, pp. 97-109, 2014.

[9] M. E. Ali, R. Das, A. Maamor, and S. B. A. Hamid, "Multifunctional carbon nanotubes (CNTs): a new dimension in environmental remediation," Advanced Materials Research, vol. 832, pp. 328-332, 2014.

[10] Z. Spitalsky, D. Tasis, K. Papagelis, and C. Galiotis, "Carbon nanotube-polymer composites: chemistry, processing, mechanical and electrical properties," Progress in Polymer Science (Oxford), vol. 35, no. 3, pp. 357-401, 2010.

[11] E. T. Thostenson, C. Li, and T.-W. Chou, "Nanocomposites in context," Composites Science and Technology, vol. 65, no. 3-4, pp. 491-516, 2005.
[12] S. Parveen, S. Rana, and R. Fangueiro, "A review on nanomaterial dispersion, microstructure, and mechanical properties of carbon nanotube and nanofiber reinforced cementitious composites," Journal of Nanomaterials, vol. 2013, Article ID 710175, 19 pages, 2013.

[13] M. Miyauchi, J. Miao, T. J. Simmons et al., "Conductive cable fibers with insulating surface prepared by coaxial electrospinning of multiwalled nanotubes and cellulose," Biomacromolecules, vol. 11, no. 9, pp. 2440-2445, 2010.

[14] U. Sahaym and M. G. Norton, "Advances in the application of nanotechnology in enabling a "hydrogen economy"', Journal of Materials Science, vol. 43, no. 16, pp. 5395-5429, 2008.

[15] Y. Zhang, Y. Bai, and B. Yan, "Functionalized carbon nanotubes for potential medicinal applications," Drug Discovery Today, vol. 15, no. 11-12, pp. 428-435, 2010.

[16] R. H. Baughman, A. A. Zakhidov, and W. A. De Heer, "Carbon nanotubes-the route toward applications," Science, vol. 297, no. 5582, pp. 787-792, 2002.

[17] J. Kong, N. R. Franklin, C. Zhou et al., "Nanotube molecular wires as chemical sensors," Science, vol. 287, no. 5453, pp. 622$625,2000$.

[18] J. E. Koehne, H. Chen, A. M. Cassell et al., "Miniaturized multiplex label-free electronic chip for rapid nucleic acid analysis based on carbon nanotube nanoelectrode arrays," Clinical Chemistry, vol. 50, no. 10, pp. 1886-1893, 2004.

[19] P.-X. Hou, C. Liu, and H.-M. Cheng, "Purification of carbon nanotubes," Carbon, vol. 46, no. 15, pp. 2003-2025, 2008.

[20] Y. Kobayashi, H. Nakashima, D. Takagi, and Y. Homma, "CVD growth of single-walled carbon nanotubes using size-controlled nanoparticle catalyst," Thin Solid Films, vol. 464-465, pp. 286289, 2004.

[21] L. Vaisman, G. Marom, and H. D. Wagner, "Dispersions of surface-modified carbon nanotubes in water-soluble and waterinsoluble polymers," Advanced Functional Materials, vol. 16, no. 3, pp. 357-363, 2006.

[22] K. A. Wepasnick, B. A. Smith, K. E. Schrote, H. K. Wilson, S. R. Diegelmann, and D. H. Fairbrother, "Surface and structural characterization of multi-walled carbon nanotubes following different oxidative treatments," Carbon, vol. 49, no. 1, pp. 24-36, 2011.

[23] A. R. Harutyunyan, B. K. Pradhan, J. Chang, G. Chen, and P. C. Eklund, "Purification of single-wall carbon nanotubes by selective microwave heating of catalyst particles," Journal of Physical Chemistry B, vol. 106, no. 34, pp. 8671-8675, 2002.

[24] B. Scheibe, E. Borowiak-Palen, and R. J. Kalenczuk, "Oxidation and reduction of multiwalled carbon nanotubes-preparation and characterization," Materials Characterization, vol. 61, no. 2, pp. 185-191, 2010.

[25] Y. Wang, H. Shan, R. H. Hauge, M. Pasquali, and R. E. Smalley, "A highly selective, one-pot purification method for singlewalled carbon nanotubes," The Journal of Physical Chemistry B, vol. 111, no. 6, pp. 1249-1252, 2007.

[26] Y. Feng, H. Zhang, Y. Hou et al., "Room temperature purification of few-walled carbon nanotubes with high yield," ACS Nano, vol. 2, no. 8, pp. 1634-1638, 2008.

[27] Y. Peng and H. Liu, "Effects of oxidation by hydrogen peroxide on the structures of multiwalled carbon nanotubes," Industrial and Engineering Chemistry Research, vol. 45, no. 19, pp. 64836488, 2006. 
[28] X. Zhao, M. Ohkohchi, S. Inoue, T. Suzuki, T. Kadoya, and Y. Ando, "Large-scale purification of single-wall carbon nanotubes prepared by electric arc discharge," Diamond and Related Materials, vol. 15, no. 4-8, pp. 1098-1102, 2006.

[29] T. Suzuki, K. Suhama, X. Zhao, S. Inoue, N. Nishikawa, and Y. Ando, "Purification of single-wall carbon nanotubes produced by arc plasma jet method," Diamond and Related Materials, vol. 16, no. 4, pp. 1116-1120, 2007.

[30] N. Karatepe and N. Yuca, "Hydrogen adsorption on carbon nanotubes purified by different methods," International Journal of Hydrogen Energy, vol. 36, no. 17, pp. 11467-11473, 2011.

[31] U. J. Kim, C. A. Furtado, X. Liu, G. Chen, and P. C. Eklund, "Raman and IR spectroscopy of chemically processed singlewalled carbon nanotubes," Journal of the American Chemical Society, vol. 127, no. 44, pp. 15437-15445, 2005.

[32] V. Datsyuk, M. Kalyva, K. Papagelis et al., "Chemical oxidation of multiwalled carbon nanotubes," Carbon, vol. 46, no. 6, pp. 833-840, 2008.

[33] C. Walling, "Fenton's reagent revisited," Accounts of Chemical Research, vol. 8, no. 4, pp. 125-131, 1975.

[34] N. M. Vesali, A. A. Khodadadi, Y. Mortazavi, A. O. Sahraei, F. Pourfayaz, and M. S. Sedghi, "Functionalization of carbon nanotubes using nitric acid oxidation and DBD plasma," World Academy of Science, Engineering and Technology, vol. 37, pp. 177179, 2009.

[35] R. A. Nyquist, Interpreting Infrared, Raman, and Nuclear Magnetic Resonance Spectra, Academic Press, 2001.

[36] J. Coates, "Interpretation of infrared spectra, a practical approach," in Encyclopedia of Analytical Chemistry, 2000.

[37] Y.-R. Shin, I.-Y. Jeon, and J.-B. Baek, "Stability of multi-walled carbon nanotubes in commonly used acidic media," Carbon, vol. 50, no. 4, pp. 1465-1476, 2012.

[38] P.-C. Ma and J.-K. Kim, Carbon nanotubes for Polymer Reinforcement, CRC Press, 2011.

[39] P. C. Eklund and K. R. Subbaswamy, "Analysis of Breit-Wigner line shapes in the Raman spectra of graphite intercalation compounds," Physical Review B, vol. 20, no. 12, pp. 5157-5161, 1979.

[40] A. C. Dillon, T. Gennett, K. M. Jones, J. L. Alleman, P. A. Parilla, and M. J. Heben, "A simple and complete purification of singlewalled carbon nanotube materials," Advanced Materials, vol. 11, no. 16, pp. 1354-1358, 1999.

[41] A. Eckmann, A. Felten, A. Mishchenko et al., "Probing the nature of defects in graphene by Raman spectroscopy," Nano Letters, vol. 12, no. 8, pp. 3925-3930, 2012.

[42] P. Hou, C. Liu, Y. Tong, S. Xu, M. Liu, and H. Cheng, "Purification of single-walled carbon nanotubes synthesized by the hydrogen arc-discharge method," Journal of Materials Research, vol. 16, no. 9, pp. 2526-2529, 2001.

[43] A. G. Rinzler, J. Liu, H. Dai et al., "Large-scale purification of single-wall carbon nanotubes: process, product, and characterization," Applied Physics A: Materials Science \& Processing, vol. 67, no. 1, pp. 29-37, 1998.

[44] R. Das, S. B. A. Hamid, M. E. Ali, S. Ramakrishna, and W. Yongzhi, "Carbon nanotubes characterization by X-ray powder diffraction-a review," Current Nanoscience, vol. 11, pp. 1-13, 2015.

[45] F. Taleshi and A. A. Hosseini, "Synthesis of uniform MgO/CNT nanorods by precipitation method," Journal of Nanostructure in Chemistry, vol. 3, no. 1, pp. 1-5, 2012. 

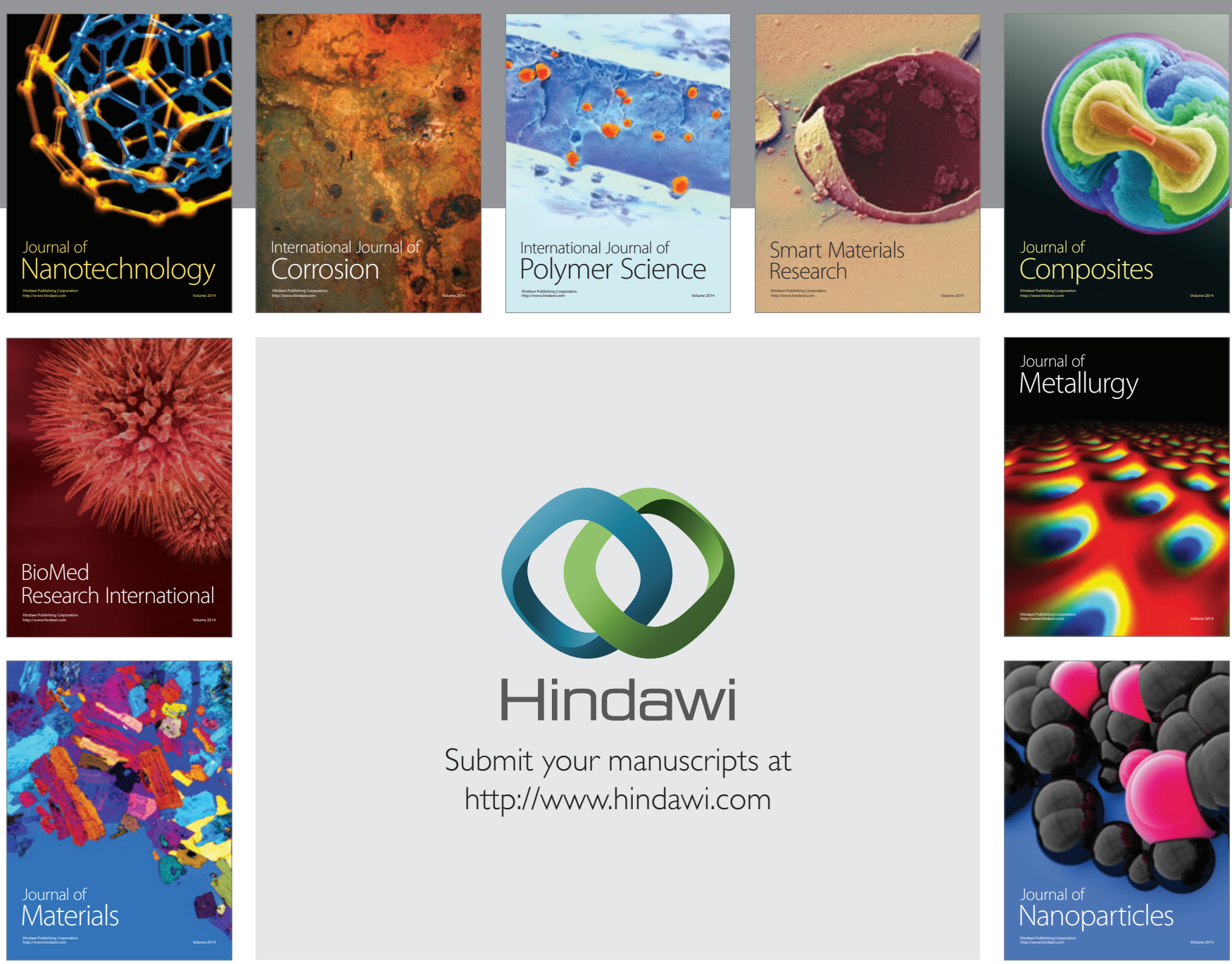

Submit your manuscripts at http://www.hindawi.com
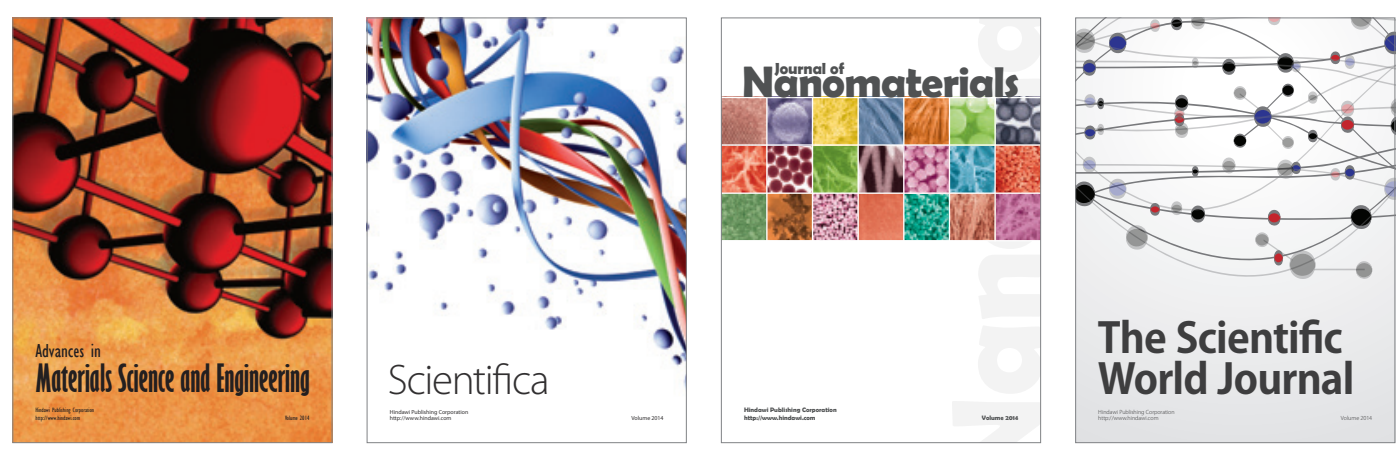

\section{The Scientific World Journal}
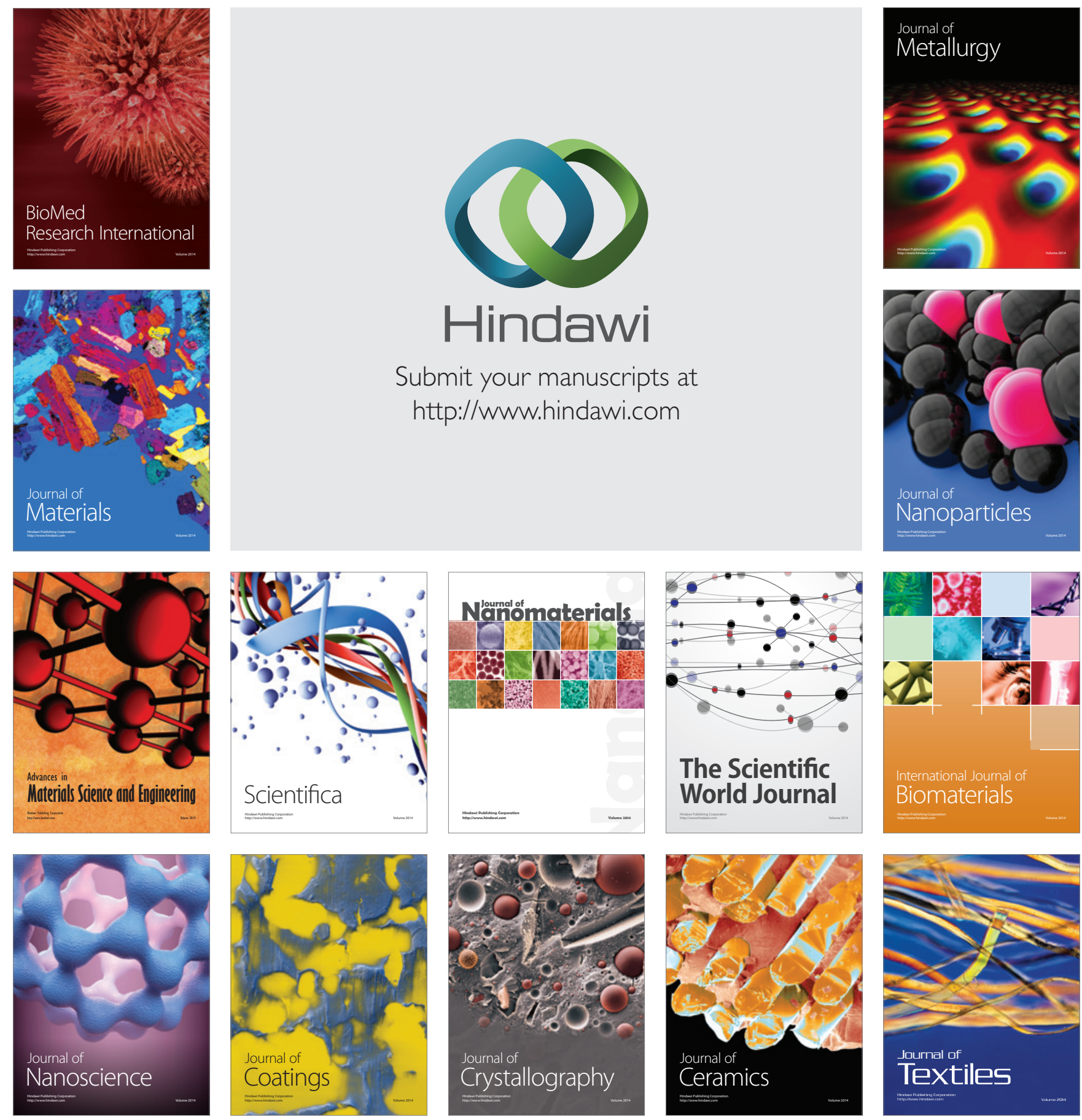